\title{
Dos grupos de discussão às redes neurais: reflexões sobre o desenvolvimento de um léxico mental ${ }^{1}$
}

Fernando G. Ferreira Júnior ${ }^{2}$

CEFET - Ouro Preto

Universidade Federal de Minas Gerais

Ao fazer uma analogia com o desenvolvimento de um grupo de discussão via email, este artigo discute a possível natureza, desenvolvimento e funcionamento do léxico mental em processos de aquisição de uma língua segundo a perspectiva conexionista. Fenômenos muito parecidos podem ser observados ao longo do processo de estruturação tanto de uma língua como de um grupo de discussão, possibilitando, dessa forma, um entendimento mais claro de teorizações conexionistas recentes acerca da linguagem, aprendizagem e de processos cognitivos em geral, no âmbito dos estudos lingüísticos (em especial na pesquisa sobre aquisição de línguas) no Brasil.

With the aim of reflecting upon the possible nature, development and workings of a mental lexicon in second language acquisition (SLA) from a connectionist perspective, an analogy is drawn between mental lexicons and the development of an email discussion group. It is argued here that similar phenomena can be observed along the structuring processes underlying both SLA and discussion groups, thus allowing for a more tangible understanding of recent connectionist theorising on language, learning and cognitive processes as a whole in the realm of the Brazilian SLA research community.

1 Este texto foi escrito como trabalho final do curso LIG-918, intitulado Aprendizagem mediada pelo computador e teorias de aquisição de linguas estrangeiras, ministrado pelo Prof. Dr. Ricardo de Souza no primeiro semestre letivo de 2004. O curso citado integra o Programa de Pós-Graduação em Estudos Lingüísticos (PosLin) da FALE/UFMG.

${ }^{2}$ Doutorando em Lingüística Aplicada pela FALE/UFMG. Contato com o autor: jr_fernando@hotmail.com 


\section{Introdução}

Neste artigo farei uma breve discussão sobre léxico mental, apontando algumas características observadas no desenvolvimento de sistemas estruturados e, particularmente, em modelos conexionistas, para o processamento e representação do conhecimento. Em modelos dessa natureza, a experiência com o meio, determinada pelo fator tempo, estabelece o grau de desenvolvimento e aprendizagem atingido. Uma língua, segundo a perspectiva conexionista, é um sistema estruturado em níveis. O grau dessa estruturação está diretamente relacionado aos padrões probabilísticos de conectividade/interação observados nos vários níveis de organização sistêmica.

Com um modelo desse tipo em mente (trocadilho mais do que adequado para a discussão a seguir), tentarei apontar possíveis semelhanças com alguns fenômenos observados ao longo do desenvolvimento de um grupo de discussão via correio eletrônico na Internet (ou seja, analisarei indícios de estruturação gradual de uma "rede" em um ambiente assíncrono de Comunicação Mediada por Computador, doravante CMC). Neste trabalho, um indicador utilizado para aferir supostos graus de conectividade da rede será o número de "fios" de discussão, identificados pelos títulos das mensagens enviadas. Inicialmente, portanto, a variável "grau de conectividade/interação" será mensurada com base nos fios de discussão e seus respectivos desdobramentos (i.e., número de mensagens geradas a partir de um fio específico). ${ }^{3}$ Apenas fios a partir de 3 mensagens serão considerados na análise feita mais adiante. Fios com 2 mensagens serão incluídos, neste trabalho, na categoria "mensagens soltas".

Infelizmente, por falta de espaço e tempo, não será feita uma análise do conteúdo das mensagens em cada fio, o que certamente poderia indicar com mais clareza os vários níveis de organização e interação atingidos pelo grupo ao longo do curso. Finalmente, é aqui

\footnotetext{
${ }^{3}$ Os fios de discussão foram gerados a partir dos arquivos do grupo de discussão (Compsla) no site Yahoo, no endereço http://groups.yahoo.com/group/compsla. As listas geradas foram, em seguida, cuidadosamente checadas pelo autor com o objetivo de eliminar mensagens duplicadas e fios indevidamente agrupados (ou seja, contendo um mesmo título, mas postados em datas e contextos diferentes).
} 
defendido que o grau de autonomia de um dado sistema (seja ele um grupo de discussão ou uma língua/interlíngua) é determinado pelo nível de interação e conectividade sistêmicas (em seus vários níveis de estruturação), numa busca constante por regularização e estabilidade. A dinâmica do sistema é resultante da constante busca por estabilidade/ regularidade entre suas partes (categorias) constituintes. O que entendemos grosseiramente por "competência", ao que tudo indica, é resultante justamente disso.

Logo abaixo, faço um relato sobre a minha experiência com o grupo de discussão e as observações que serviram de insight para este texto. Mais adiante, de maneira bastante concisa, faço alguns comentários sobre redes conexionistas e, em seguida, uma discussão acerca da natureza e funcionamento de um léxico mental. Posteriormente são exibidos os dados quantitativos referentes ao grupo de discussão (i.e., número total de mensagens, número de fios, número de mensagens nos fios, número de mensagens soltas) e, em seguida, faço uma comparação entre o desenvolvimento do grupo de discussão (revelado pelos dados quantitativos) e a estruturação de uma rede (ou léxico mental) nos moldes conexionistas, como discutido anteriormente. Por último, teço algumas considerações finais sobre a concepção conexionista de representação e processamento da linguagem e sua importância para a área de aquisição de segunda língua (SLA).

\section{Observações sobre o desenvolvimento de um grupo de discussão}

Durante o primeiro semestre de 2004, o Programa de PósGraduação em Estudos Lingüísticos (PosLin) da Faculdade de Letras (FALE) da Universidade Federal de Minas Gerais (UFMG) ofereceu um curso online intitulado "Aprendizagem mediada pelo computador e teorias de aquisição de línguas estrangeiras". Toda a interação entre os participantes do curso (professor e alunos) ao longo das quinze semanas de trabalho se deu por meio de uma lista de discussão via correio eletrônico (aqui chamada de grupo de discussão) e um fórum eletrônico em que eram publicadas as resenhas das leituras feitas ao longo de todo o curso por cada membro. As reflexões feitas ao longo 
deste trabalho baseiam-se apenas nos dados relativos ao grupo de discussão. ${ }^{4}$

O grupo de discussão, aberto oficialmente com a postagem da primeira mensagem pelo professor do curso em 16/03/2004 e encerrado no dia 13/07/2004, era inicialmente composto de 29 alunos, nas categorias de "aluno regular", "aluno em disciplina eletiva" e "aluno em disciplina isolada". Na última semana do curso havia 15 alunos ativos no nosso grupo de discussão. A maior parte dos participantes não se conhecia anteriormente. O conteúdo das mensagens era sempre relacionado às leituras da semana e abordava tópicos teóricos e práticos em SLA and CALL, respectivamente.

As mensagens enviadas ao grupo de discussão na primeira semana refletem uma certa "confusão sistêmica", deixando transparecer o quão "frouxa" estava a relação entre os integrantes do grupo, bem como o próprio "senso de localização" de cada aluno, como exemplificados nos trechos a seguir: ${ }^{5}$

a) No material em que foi enviado para mim não tem a resenha feita por você que foi indicada no site do curso. Não teria como você me enviá-la por e-mail? (23/03/2004).

b) (...) algumas pessoas podem estar interpretando a data e horário limite de entrega da resenha como sendo meia-noite de amanhã (quarta-feira). Se tal mal entendido estiver de fato acontecendo, talvez seja por causa de meu uso da expressão "0 hora de quarta-feira". Peço-lhes atenção para o fato de que 0 hora significa nenhum minuto adentro do dia em questão,

\footnotetext{
${ }^{4}$ Embora a discussão aqui feita não tenha utilizado os dados presentes no fórum eletrônico do curso, é certo que as resenhas e textos lá publicados tenham fomentado "a discussão e o debate coletivos acerca de perspectivas individuais" sobre os temas e teorizações discutidos, como destacado pelo próprio professor no site do curso ao mencionar o objetivo de tal fórum. Este trabalho, portanto, reconhece a potencial contribuição do fórum na interação observada entre os participantes no âmbito do grupo de discussão.

${ }^{5}$ Ao longo deste trabalho, sempre que nomes de membros do grupo de discussão forem mencionados nos trechos transcritos das discussões, apenas a letra inicial de seus nomes será mantida.
} 
portanto na hora de integralização da vigésima-quarta hora do dia anterior. Conclusão: o horário limite da primeira resenha é meia-noite de terça-feira (...) (23/03/2004).

c) Gostaria de lembrar-lhes que o meio de comunicação mediada pelo computador destinado ao envio de resenhas é o fórum eletrônico de nosso curso. (25/03/2004).

d) Peço desculpas pela falha de ter enviado a resenha para o grupo por email. Pelo menos, resta o consolo que ainda tenho 34 chances para acertar! (26/03/2004).

e) Bem, gostaria de dizer o mesmo e acrescentar que durante essas duas semanas iniciais do curso (essa e a anterior) minha mente está um tanto quanto bagunçada devido à tempestade de novas informações e exigências que está despencando sobre $\operatorname{mim}(26 / 03 / 2004)$.

f) Acho que a sensação que $\mathrm{R}$ relata pode estar sendo compartilhada por outras pessoas. O que eu tenho a dizer é que, sinceramente, acho natural que se tenha um pouco esta sensação. O volume de informações é de fato muito grande, há uma longa tradição de pesquisa e de formulações teóricas sendo evocada direta ou indiretamente nos temas levantados em nossa discussão, e para aqueles que se defrontam com este tipo de reflexão pela primeira vez ou que têm ainda pouca familiaridade com ela, a vivência do processo como bastante exigente é real. (26/03/2004).

Transcorridos cerca de $85 \%$ do tempo do curso, ou seja, entre as $12^{\underline{a}}$ e $13^{\underline{a}}$ semanas, houve uma certa inquietação por parte de algumas pessoas do grupo sobre questões pragmáticas que emergiram na interação em nosso grupo de discussão, em especial o silêncio (i.e., ausência de um feedback), mensagens dirigidas a um membro específico (pares adjacentes) e uma série de questões relativas a um nível de interação mais abstrato. Cito abaixo alguns trechos que revelam o éthos do grupo nesse estágio mais complexo de desenvolvimento sistêmico:

g) Foi muito bom ter compartilhado com a gente a sua visão sobre o nosso "estilo" nas interações e como alguns aspectos 
destas estão relacionados com os textos que lemos nesta semana. Acho que todos percebemos, uma hora ou outra, como o conteúdo dos textos nos remete às nossas próprias práticas discursivas. Tais práticas, acredito eu, são moldadas também pelo grau de familiaridade que temos um com o outro. Eu, por exemplo, não os conheço pessoalmente e esse fato é determinante para o modo como venho interagindo com vocês. Acho que tenho procurado, não sei de forma consciente ou não, ajustar meu discurso àquele que percebo ser o recorrente nas nossas interações. A imagem que tenho de vocês está espelhada no discurso de cada um e isso, se não for relevante, está no mínimo relacionado com as formas de interação e como conseqüência, tem relevância para o processo de aprendizagem. O que vocês acham? (15/06/2004)

h) Seria interessante analisar também a construção das identidades sociais ao longo do curso. Podemos verificar que cada um de nós, inconscientemente, fornece informações sobre nós mesmos através do nosso discurso (nossos posicionamentos, nossas opiniões, nosso jeito de ser, crenças, posicionamento teórico, formação acadêmica, etc.). (15/06/2004)

i) Concordo com você E e, mais uma vez, fico muito feliz em perceber que nossas experiências durante o curso se assemelham. À medida que fomos nos "conhecendo" melhor fomos moldando o estilo de nosso discurso. (16/06/2004)

j) Você diz que no início do curso o seu jornal não gerou uma resposta sequer, mas você está esquecendo de dois dados muitíssimo importantes: primeiro - o silêncio do grupo, embora tenha te deixado frustrado, foi uma resposta. Uma resposta que te fez mudar de estilo assim como os participantes do estudo de Davis e Thiede. Todos nós, de uma forma ou de outra, tivemos que nos adaptar às peculiaridades da interação mediada por computador. (17/06/2004)

k) Raramente pedimos a participação efetiva do R (e até nos referimos a ele na terceira pessoa!!!). Analisando as intervenções dele, elas eram mais freqüentes no início do curso e agora, como ele mesmo apontou, os alunos é que "mediam" a interação. (17/06/2004) 
1) Nossa comunidade de aprendizagem já há algum tempo ganhou vida própria. Para mim, nada poderia ser tão satisfatório! (17/06/2004)

m) Acho que podemos encontrar pares adjacentes com clareza, mas é possível que tenham características próprias. Não sei se o silêncio vai significar apenas uma coisa. Nem sempre concordância e discordância são apresentadas e às vezes aparecem bem mitigadas para não confrontar a face "virtual" dos participantes (pelo menos no nosso grupo). Acho que são respostas específicas e às vezes um conjunto. (18/06/2004)

n) Compreendo sua sensação de estar falando para as paredes. No entanto, acho que aprendemos em nosso curso sobre subjetividade que é normal nosso discurso "bater" ou não com as expectativas das pessoas porque fatores como interdiscurso, formação discursiva, etc. têm papel preponderante. Há muitas variáveis a serem consideradas antes de acharmos que nossa fala não é relevante. O F, de outra perspectiva, analisou metaforicamente o processo de crescimento do grupo. Foi um texto de arrepiar e, nem por isso respondi. Li, fiquei maravilhada e achei que não carecia mais dizer. (20/06/2004)

O que vemos claramente nos últimos trechos $(g, h, i, j, k, l, m \mathrm{e}$ $n)$ é uma preocupação com questões mais abstratas das interações do grupo (bastante diferentes daquelas do início das discussões - trechos $a, b, c, d$, e e $f-$, ou seja, que refletiam preocupações de natureza linear, direta, mecânica, relativas ao "aqui e agora"). Os comentários nos últimos trechos citados acima refletem, ao meu ver, um nível de interação bastante complexo entre os sujeitos do grupo. Este trabalho busca justamente verificar esses diferentes graus de interação do grupo, como evidenciado pelo comportamento do grupo no início e nas semanas finais do curso, e suas possíveis relações com os "fios" das mensagens enviadas. Essa discussão será retomada mais adiante. A seguir, é feita uma reflexão sobre redes conexionistas para o processamento e representação do conhecimento. A discussão baseiase, principalmente, em Elman et al. (1998). 


\section{Desenvolvimento, representação e processamento do conhecimento de uma perspectiva conexionista.}

Uma rede conexionista ${ }^{6}$ é formada, basicamente, por unidades (numa analogia com nossos neurônios) interligadas umas às outras através de conexões (analogia com sinapses), um enfoque, portanto, fortemente apoiado na neurofisiologia humana. O processamento dessa rede é totalmente distribuído e em paralelo (daí o termo sinônimo de rede PDP, ou seja, processamento distribuído em paralelo). Modelos conexionistas, com uma arquitetura interna como a descrita acima, são construídos na forma de programas de computador. Uma vez em funcionamento, o sistema estabelece processos de regulação entre as unidades que compõem a rede (na forma de ajuste das forças/pesos de conexão), provocando, assim, a estruturação do sistema. O 'conhecimento' da rede está justamente nas forças/pesos definidos localmente entre as unidades (i.e., através da constante ativação ou inibição destas). Assim, surge um desempenho baseado em padrões de ativação entre unidades da rede, padrões estes que estabelecem configurações específicas a cada ativação.

Basicamente, há três tipos de unidades em uma rede: as unidades de insumo, as unidades ocultas e as unidades de saída. É na camada oculta que as representações são criadas e o conhecimento é gerado. A rede estabelece associações através da regulação entre o seu peso/ forma atual e o peso/forma ideal, este último informado, inicialmente, pela experiência com o meio. Os pesos entre as unidades (e a conseqüente estabilização da rede, ou a aprendizagem propriamente dita) em um modelo conexionista são auto-reguláveis. Assim a rede vai, aos poucos, auto-regulando-se e refinando positivamente o limiar de ativação (em outras palavras, refinar significa corrigir a diferença - o erro - entre produção atual e produção ideal). Visto dessa maneira, o erro (e a sua constante minimização) torna-se fundamental para a rede atingir a produção ideal. A rede atinge a generalização de padrões a

\footnotetext{
${ }^{6}$ O conceito sinônimo de "redes neurais", implicando uma possível plausibilidade biológica devido à metáfora do cérebro em funcionamento, através de neurônios e sinapses, também é usado nas teorizações de cunho conexionista sobre a estrutura e o funcionamento do sistema cognitivo humano.
} 
partir da exposição gradual ao padrão ideal desejado. A cada produção da rede é feita uma associação com o padrão ideal. O cálculo da diferença entre os pesos refaz o caminho de forma inversa. Essa retropropagação faz com que o cálculo retorne para as unidades ocultas, de forma que haja uma regulação e um reajuste, visando às futuras ativações (esse é um processo de constante minimização do erro por parte da rede). Dessa forma, a rede aprende a aprender, através da diminuição da sensibilidade ao erro (i.e., torna-se um sistema mais tolerante e menos maleável).

Há uma questão importante nessa discussão. Como destacam Elman et al. (1998), as associações de padrões idênticos nos primeiros modelos conexionistas (como o Perceptron) só podiam ocorrer em um campo espacial linear, ou bidimensional. Isso fazia com que a rede ignorasse o fato de que, às vezes, formas diferentes podem revelar padrões de comportamento idênticos (e vice-versa). Modelos do tipo Perceptron tinham apenas duas camadas (níveis) de unidades, ou seja, unidades de entrada e unidades de saída, e isso tornava o comportamento da rede algo parecido com o estímulo/resposta do behaviorismo. Em um modelo Perceptron, as associações são puramente mecânicas. É necessário, portanto, um nível de processamento que gere representações abstratas.

Para tentar resolver tal problema (i.e., não cair em um mero 'associacionismo computacional'), Elman et al. (1998) e Elman (2004) propõem uma rede do tipo SRN (simple recurrent network), que possui, além de uma camada de unidades intermediária (oculta) responsável pelo aspecto "abstração" ou "representações abstratas" numa rede, uma camada ou unidades de contexto, adicionando, assim, o aspecto tempo ou uma memória à rede (devido à recursividade). Assim, nas redes recorrentes, as unidades são informadas não apenas pelo insumo externo a elas, mas também por ativações prévias da própria unidade que ficam "registradas" nas unidades de contexto, aumentado o poder de auto-regulação. E isso é uma importante contribuição conexionista para a discussão sobre autonomia. A rede produz, assim, insumo que, por sua vez, regulará a própria rede. Também, inerente a uma rede recorrente é a sua capacidade de "inferir" (esse aspecto é consoante com a aprendizagem em vários domínios e reflete a capacidade de "fazer previsões" - certamente conseqüência direta do estabelecimento de protótipos ou configurações padrão). 
Processos de associação de padrões numa rede conexionista tipo SRN tornam-se mais dinâmicos, pois o que é "similar" não mais será definido em um ambiente bidimensional (baseado puramente na forma), mas multidimensional (sendo consideradas também relações espaciais). Dessa maneira, aumenta-se a capacidade de representação e, conseqüentemente, de associação. Podemos dizer que tais redes também exibem um comportamento inteligente, pois possuem níveis diferentes de abstração/representação do conhecimento gerado.

A rede funciona sempre levando em conta restrições das mais variadas ordens, sejam restrições presentes no insumo ao qual ela está constantemente exposta, ou nas próprias restrições sistêmicas por ela criadas ao longo de seu desenvolvimento (ou seja, a sua língua interna ou 'interlíngua'). É a partir dessas restrições que a rede emerge ou, em outros termos, o sistema é construído. É a partir de processos de restrições de restrições que se dá a regulação do sistema, levando em última instância a uma auto-regulação (autonomia) e uma certa consolidação da aprendizagem.

Para concluir, é importante destacar que em uma rede conexionista o importante são as representações locais, i.e., as conexões entre as unidades. É a partir da força inicialmente estabelecida localmente que se dá um processo de equilíbrio da rede. E é a partir do equilíbrio da rede que surgem as representações distribuídas. Ou seja, representações locais geram representações emergentes (ou ativas) e distribuídas, determinadas sempre, por sua vez, por aquelas mesmas configurações localmente e constantemente (re)definidas através de pesos (forças) entre as conexões.

\section{O léxico: de um dicionário a estados mentais}

Embora o próprio conceito de palavra seja algo altamente controverso (veja SINGLETON, 1999), é certo que as palavras desempenham um papel muito mais importante no desenvolvimento e estruturação de uma língua do que muitos teóricos parecem admitir (para uma melhor compreensão do papel das construções lexicais na estruturação da linguagem, veja as recentes contribuições de NICK ELLIS, 2001, 2003). Há um verdadeiro abismo entre teorizações ortodoxas que vêem o léxico como um simples dicionário, do qual as palavras são escolhidas para o preenchimento de estruturas sintáticas 
no uso da linguagem (veja PINKER, 1994), e reflexões conexionistas recentes que preconizam que palavras são "dicas" ou "estímulos" que provocam mudanças em estados/configurações mentais (ELMAN, 2004). Discutirei mais detalhadamente estas últimas teorizações, de natureza mais abstrata, mais adiante.

Como uma transição suave para a recente alternativa conexionista de Elman, começaremos com uma conceituação de léxico mental que pode ser caracterizada como um enorme avanço em relação às teorizações ortodoxas que vêem o léxico como um simples dicionário ou depósito de palavras usadas, principalmente, a serviço de estruturas sintáticas.

Para Meara (1996), um léxico mental pode ser entendido a partir de duas dimensões básicas: tamanho e grau de conectividade. Ao adquirirmos novas palavras na L2 (pela exposição ao insumo), adquirimos também um conhecimento mais amplo sobre as palavras que já conhecemos. Mas o tamanho do vocabulário, por si só, não é um bom indicativo da competência em L2. À medida que o léxico cresce, o tamanho torna-se algo de menor importância. Meara enfatiza a importância do grau de organização desse vocabulário. É necessário entender o léxico de uma perspectiva sistêmica, levando em conta não apenas o tamanho do vocabulário, mas o nível de profundidadedesse conhecimento. Isso requer que olhemos para a dimensão da organização (ou seja, algo que diferencie alguém que conhece apenas uma longa lista de palavras daquele outro aprendiz, cujo vocabulário é estruturado em termos de vastas redes de associação entre as palavras). Tais associações podem ser paradigmáticas, sintagmáticas, situacionais, emocionais, mas todas contribuem, de maneiras diferentes, para o significado de uma palavra. Para Meara, tais tipos de conexões são o que precisamente distingue um verdadeiro léxico mental de uma simples lista de palavras (p.48).

Estruturação, portanto, é uma palavra chave na discussão sobre léxico em L2, sugerindo, assim, que o grau de estruturação lexical relaciona-se diretamente com o nível de proficiência do aprendiz. Não que todas as palavras tenham conexões umas com as outras, mas simplesmente que o padrão de conexão precisa ser rico o suficiente para permitir o estabelecimento, de forma fácil e eficaz, de conexões entre partes diferentes do léxico. Dessa forma, Meara mostra que é possível descrever um léxico em duas dimensões distintas, que nos 
possibilita distinguir, por exemplo, entre um vocabulário grande e desestruturado e um outro pequeno, mas altamente estruturado (veja que é o nível de estruturação que determina o desempenho do aprendiz na L2, como falado anteriormente). A noção sistêmica de léxico mental proposta por Meara difere radicalmente das teorizações tradicionais. Um léxico mental não pode ser entendido como coleções de itens ou palavras específicos, mas como um sistema (rede) de conexões altamente estruturado.

De uma perspectiva conexionista, ou emergentista, Elman (2004) propõe uma visão ainda mais dinâmica e funcional acerca da natureza da representação e funcionamento de um léxico mental. Elman sugere que palavras não são coisas que contêm significados fixos armazenados em nossa memória de longo prazo, como nos leva a crer o conceito tradicional de léxico mental. Para Elman, uma palavra não carrega em si um significado, mas sim "dicas" ou "pistas" para significados que, no fundo, se resumem a configurações ou estados mentais específicos. Nesse sentido, palavras equivaleriam a estímulos sensoriais que atuam em nossos estados mentais, determinando, assim, o tipo de significado instanciado. Em um sistema dessa natureza, o tempo é um fator crucial. O desenvolvimento do sistema (no caso, nosso léxico mental) depende da recorrência de certos padrões e seus respectivos estímulos. Dessa relação, categorias são criadas e generalizações e conexões, de base probabilística, são estabelecidas.

A teorização sistêmica de Meara acima discutida aproxima-se, mesmo que timidamente, dos insights conexionistas de Elman. Tamanho e grau de conectividade são dimensões cruciais para que categorias sejam estabelecidas e significados sejam continuamente (re)criados e refinados, possibilitando, por sua vez, que interpretações novas e mais complexas sejam geradas.

Para Elman, as palavras (e seus respectivos significados) são regiões de ativação específicas ao longo do "espaço mental" de uma rede. Variações espaciais implicam mudanças/distinções de significado, sendo tais espaços preenchidos hierarquicamente de forma esquemática/ prototípica. Essas variações espaciais, é importante destacar, equivalem a pesos ou restrições de base probabilística em uma rede conexionista. Dependendo do estímulo (contexto), categorias, subcategorias e níveis extremamente sutis de significado são ativados. Dessa forma, as 
"propriedades de uma palavra são reveladas pelos efeitos que estas causam em estados mentais" (p.302). Tais efeitos, por sua vez, são regulados pelo contexto, como destacado acima.

A concepção de representação proposta por Elman redefine de maneira precisa a distinção tradicional entre type e token e os variados níveis de abstração lexemáticos (veja SINGLETON, op. cit, p.10). Como vimos acima, cada sentido de uma palavra resulta de uma configuração mental específica. Tomemos como exemplo a palavra carro na frase "o carro passou e quebrou o carro da criança". Essas duas ocorrências de carro, ou seja, esses dois tokens, não serão, em termos mentais, os mesmos types. Os estados mentais serão diferentes. Como destaca Elman (p.302), cada configuração mental gerada pela palavra carro ocupa um determinado espaço mental ( $a$ bounded region) reservado aos membros desse lexema. Pequenas variações dentro dessa área lexemática implicam variações sutis de significado. Cada ocorrência da palavra carro produzirá, portanto, uma determinada configuração nessa microrregião a ele dedicada. Tal variação, por sua vez, reflete alterações e "instabilidades ao longo de diferentes eixos espaciais" (p.304), correspondentes a informações sobre número, papel temático (sujeito, objeto, etc.), flexão, etc. Um único lexema instanciado em contextos diferentes produzirá significados também diferentes.

O mesmo tipo de processo acima descrito aplica-se aos mais variados tipos de categorias criadas. Verbos e substantivos, por exemplo, ocupam regiões espaciais específicas. Como a representação é esquemática e hierárquica, subcategorias são criadas. Vejamos um exemplo corriqueiro para a categoria substantivo:

[substantivos [animados [animais [rato, gato, cachorro] [monstro, leão, tigre] [humanos [mulher, garota,], [homem, garoto] ] ] ] [inanimados [comida [sanduíche, biscoito, pão] ] [quebráveis [prato, copo] ] ]].

Os significados emergem em conseqüência de sua localização específica em um espaço multidimensional no qual "diferentes dimensões podem ser alocadas enquanto outras são ignoradas" (p.304), dependendo do contexto. Veja a Figura 1 a seguir: 


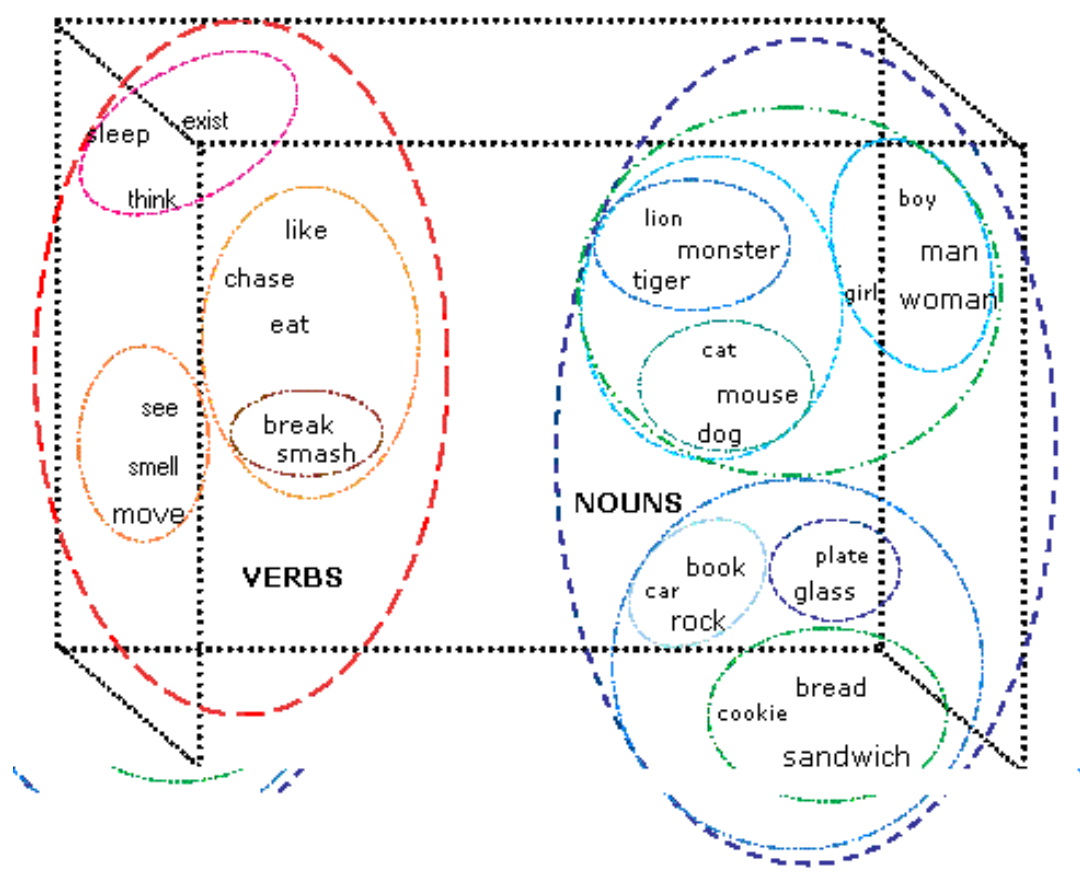

FIGURA 1 - Visualização esquemática, em 3D, do estado espacial multidimensional gerado pela camada oculta de uma rede conexionista do tipo SRN. O estado espacial é dividido em diferentes regiões que correspondem a categorias gramaticais e semânticas. Relações de aninhamento espacial (por ex., a categoria homem está contida na categoria animado que, por sua vez, está contida na categoria substantivo) refletem relações hierárquicas entre as categorias. In: Jeffrey L. Elman (2004), An alternative view of the mental lexicon. Trends in Cognitive Science, v. 8, n.7, p. 304.

Resumindo nossa discussão teórica até este ponto, vimos, anteriormente, aspectos básicos de funcionamento de modelos conexionistas e as novas maneiras de compreendermos o desenvolvimento e a estruturação de sistemas complexos possibilitadas por esses modelos. Também vimos uma nova forma de entender como se dá a representação do conhecimento, partindo do pressuposto de que todo conhecimento é, por natureza, distribuído e emergente. Em seguida, numa rápida discussão, abordamos diferentes concepções sobre léxico mental, desde teorizações ortodoxas que concebem o léxico como um simples depósito de palavras na memória de longo 
prazo, passando por teorizações mais sistêmicas e dinâmicas (porém limitadas em termos explicativos) e culminando na concepção de léxico de Elman acima discutida, para o qual as palavras, em si, não possuem significados, mas servem de dicas, estímulos para determinados padrões de ativação em espaços mentais altamente dinâmicos. A seguir retomo a nossa discussão iniciada anteriormente sobre grupos de discussão, tentando estabelecer relações entre o desenvolvimento destes com características observadas no desenvolvimento de redes conexionistas.

\section{O grupo de discussão entendido como uma rede (ou léxico) conexionista}

Acredito, como comentado no início deste artigo, ser possível pensar o desenvolvimento do nosso grupo de discussão com base nas mesmas características observadas no desenvolvimento de redes conexionistas (como vimos na proposta de léxico mental de Elman). As dimensões tamanho e grau de conectividade (sugeridas por Meara) podem, também, ser aplicadas, grosso modo, ao número de mensagens postadas ao longo do desenvolvimento do grupo de discussão.

No início do curso, apesar de o grupo de discussão contar com 29 sujeitos, o nível de interação era muito pequeno. Com o passar do tempo, apesar da redução gradual (embora considerável) do número de sujeitos (ou seja, somente quinze permaneceram até o final do curso, o que representa uma redução da ordem de quase 50\%), houve um aumento expressivo no número de mensagens postadas, seguido por um período de estabilização/equilíbrio, mas não a sua diminuição. Isso reflete o contato gradual do grupo com mais e mais insumo (ou seja, as leituras semanais do curso). Ao todo, excluídas as mensagens duplamente postadas, foram enviadas 1.329 mensagens. Destas, 927 faziam parte dos 123 fios identificados ao longo do curso. As 402 mensagens restantes foram classificadas como "mensagens soltas", pois continham apenas 1 ou 2 mensagens por fio.

Numa analogia com a teorização de Elman, podemos especular que o grupo de discussão, como uma "rede", exibiu um comportamento semelhante àquele verificado em processos de categorização. O Gráfico 1 a seguir é o primeiro indício de que o grupo foi, gradualmente, 
estabelecendo níveis de interação cada vez mais complexos. Na análise dos fios de discussão, Gráfico 2, mais abaixo, temos uma noção mais precisa do grau de interação do grupo ao longo de sua estruturação. A interpretação e discussão dos dados ilustrados nos gráficos abaixo será feita a seguir.

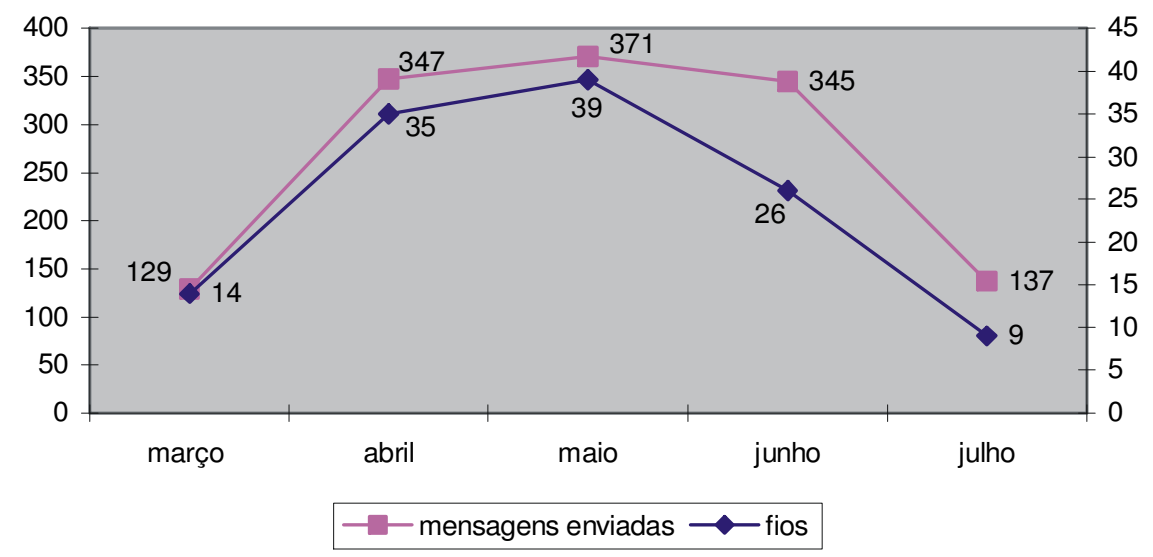

GRÁFICO 1: Número total de mensagens enviadas e fios gerados

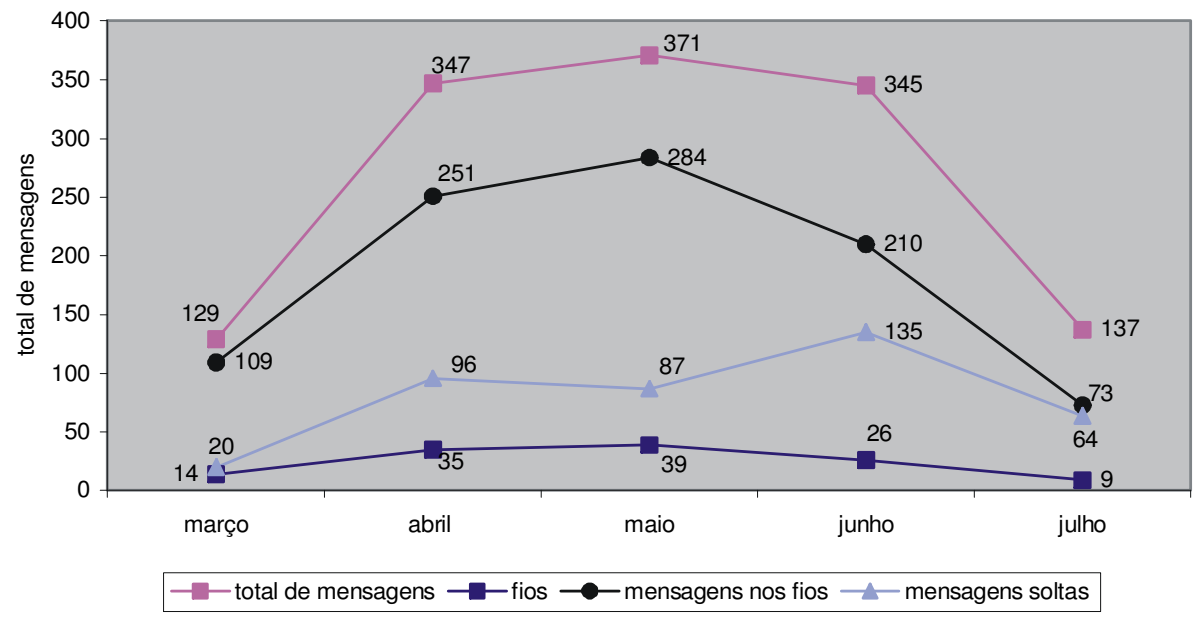

GRÁFICO 2: Comparação entre mensagens enviadas nos fios gerados e mensagens soltas (sem fio) 


\section{Discussão}

Como mostram os Gráficos 1 e 2 acima, no início do curso o número de fios de discussão era pequeno (14 fios em março), teve um aumento agudo em abril (35 fios) e continuou aumentando até atingir seu pico no final do mês de maio (39 fios). Em seguida, o número de fios entrou em um processo gradual de queda, embora constante, nos meses de junho (26 fios) e julho ( 9 fios). Por outro lado, é interessante observar a relação entre o número de mensagens nos fios e o total de mensagens enviadas em cada mês: 109 em março (ou 84.5\% das mensagens), $251 \mathrm{em}$ abril (72.4\% das mensagens), $284 \mathrm{em}$ maio (76.7\% das mensagens), 210 em junho (61\% das mensagens) e 73 em julho (53.3\% das mensagens). Como podemos entender os números acima? Por exemplo, os meses de março e julho (respectivamente, o primeiro e o último mês de curso) tiveram praticamente o mesmo número de dias de discussão (10 dias em média), no entanto há uma diferença enorme entre o número de mensagens nos fios e o número de mensagens soltas nesses dois meses. Veja Tabela 1 abaixo:

\section{TABELA 1}

Número total de mensagens enviadas, fios identificados, mensagens nos fios e mensagens soltas no período de março a abril e seus respectivos percentuais.

\begin{tabular}{|c|c|c|c|c|}
\hline & $\begin{array}{l}\text { Total de } \\
\text { mensagens }\end{array}$ & $\begin{array}{l}\text { Número } \\
\text { de fios }\end{array}$ & $\begin{array}{l}\text { Número de mensagens } \\
\text { nos fios e seu percentual }\end{array}$ & $\begin{array}{l}\text { Número de mensagens } \\
\text { soltas e seu percentual }\end{array}$ \\
\hline \multirow[t]{2}{*}{ Março } & 129 & 14 & 109 & 20 \\
\hline & 347 & 35 & $\begin{array}{c}\text { (84.5\% das mensagens) } \\
251\end{array}$ & $\begin{array}{c}\text { (15.5\% das mensagens) } \\
96\end{array}$ \\
\hline Abril & & & (72.4\% das mensagens) & (27.6\% das mensagens) \\
\hline \multirow[t]{2}{*}{ Maio } & 371 & 39 & 284 & 87 \\
\hline & & & (76.7\% das mensagens) & (23.3\% das mensagens) \\
\hline \multirow[t]{2}{*}{ Junho } & 345 & 26 & 210 & 135 \\
\hline & & & (60.1\% das mensagens) & (39.2\% das mensagens) \\
\hline \multirow[t]{2}{*}{ Julho } & 137 & 9 & 73 & 64 \\
\hline & & & (53.2\% das mensagens) & (46.8\% das mensagens) \\
\hline
\end{tabular}

Há uma explicação óbvia para a diferença apontada acima. Em março havia 29 pessoas no grupo, portanto o número de mensagens postadas nos fios e soltas, teoricamente, tem que ser maior do que em 
julho, mês em que havia apenas 15 pessoas no grupo. E isso parece explicar, justamente, a diferença entre os números desses dois meses. Mas olhando os dados com mais atenção, vemos um fenômeno interessante: as mensagens soltas no mês de março equivalem apenas a $15.5 \%$ do total de mensagens enviado, ao passo que as mensagens soltas no mês de julho equivalem a $46.8 \%$ do total enviado. Esse é um dado importante, se analisarmos a característica dos fios ao longo do curso. É justamente a característica e o comportamento dos fios que discutiremos a seguir.

No início do curso, apesar do número maior de sujeitos no grupo, poucas mensagens eram postadas fora dos fios. Os fios, por sua vez, eram quase todos iniciados pelo professor do curso. No mês de março, quase todos os fios foram iniciados pelo professor do curso (ou seja, onze dos quatorze fios identificados). Por isso observamos, na tabela 1 acima, o número baixo de mensagens soltas em comparação com as mensagens nos fios. Ou seja, a rede (grupo) era bastante desestruturada, uma certa Babel. Os fios gerados pelo professor tinham justamente a função de estabelecer conexões ante um caos aparente de formas variadas, daí a necessidade maior de intervenção, de mediação do professor. A mediação dele, naquele estágio, era crucial, pois tratava de conectar/ligar as partes e estabelecer relações ou associações, sempre na busca de uma otimização do sentido/significado em nossa comunicação eletrônica assíncrona. Como em uma rede conexionista do tipo Perceptron, as relações nessa fase de desenvolvimento do grupo eram essencialmente lineares, diretas, mecânicas, ou relações em um espaço de representação bidimensional, como comentado anteriormente.

\section{Processos de categorização: subfios dos fios}

No mês de abril o comportamento do grupo começou a mudar. Dos 35 fios gerados, apenas nove foram gerados a partir do professor. Começou a haver uma explosão de mensagens nos fios (251 mensagens, como ilustrado no Gráfico 2). No mês de maio, dos 39 fios gerados, apenas 10 partiram do professor (e, novamente, houve um aumento no número de mensagens nos fios nesse mês, chegando a 284 mensagens). Por outro lado, houve uma ligeira diminuição no número de mensagens soltas. O Gráfico 3 mostra o desenvolvimento dos fios 
ao longo dos meses, subdividindo-os em fios gerados pelo professor e fios gerados pelo grupo.

GRÁFICO 3: Origem dos fios gerados ao longo dos meses

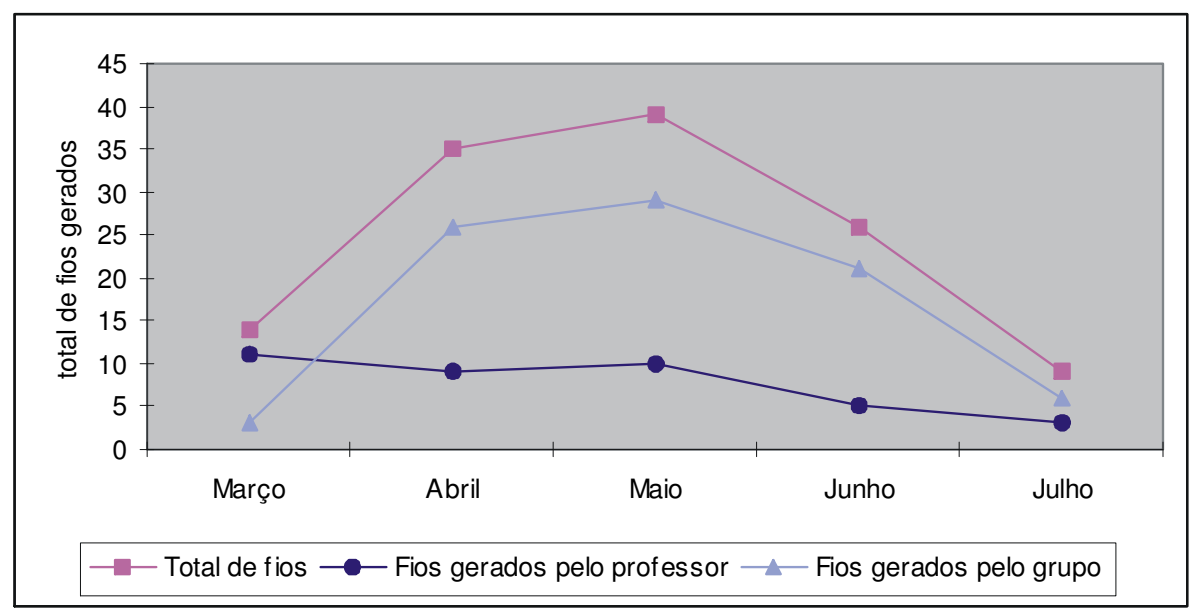

O gráfico acima ilustra bem o desenvolvimento do grupo. À medida que o sistema se desenvolve, ele torna-se mais complexo, e mais complexas vão ficando as suas relações (ou seja, categorias são criadas e níveis refinados, como vimos na discussão sobre redes conexionistas). As relações tornam-se mais abstratas, pois passam a se dar de forma indireta (daí a importância de uma representação multidimensional, como vimos na proposta de Elman).

O número baixo de mensagens nos fios gerados no mês de julho não indica uma diminuição no grau de conectividade do grupo de discussão. Como pode-se observar mais claramente no mês de março, os fios captam apenas relações lineares. A diminuição dos fios e sua respectivas mensagens coincide justamente com um aumento de mensagens entre sujeitos específicos (ou seja, pequenas sub-redes ou categorias parecem ser criadas), evidenciado pelos títulos dos fios a partir do mês de abril. Além disso, os longos fios (inicialmente comuns) passam a gerar sub-fios ou fios menores, entretanto visivelmente interrelacionados, como nos exemplos do Quadro 1 a seguir. 


\section{QUADRO 1}

Exemplos das inter-relações entre fios e subfios gerados

Fio 1 - Lantolf e Pavlenko (gerado no dia 26/04, com 11 mensagens)

Fio 1.1 - A respeito de Lantolf e Pavlenko (gerado no dia 27/04, com 7 mensagens)

Fio 1.2 - Texto de Lantolf (gerado no dia 27/04, com 5 mensagens)

Fio 1.3 - Barcelos e Pavlenko (28/04, com 3 mensagens)

Fio 1 - Crenças do aprendiz e teoria da atividade (em 26/04, com 6 mensagens)

Fio 1.1 - "Capturando" crenças (em 27/04, com 3 mensagens)

Fio 1.2 - Crenças (em 04/05, com 3 mensagens)

Fio 2 - Contexto sociocultural (gerado no dia 04/05, com 8 mensagens)

Fio 1.2.1 - Crenças e contexto sociocultural (gerado em 05/05, com 3 mensagens)

Fio 1 - Swain: output (gerado no dia 08/06, com 10 mensagens)

Fio 1.1 - Vygotsky + Swain (gerado no dia 09/06, com 8 mensagens)

Fio 1.2 - Input, output e além (gerado em11/06, com 4 mensagens)

É justamente no estágio acima descrito, de alta conectividade no grupo de discussão (por volta de meados do mês de junho), que surgem as preocupações de ordem pragmática nas discussões do grupo, como vimos nos trechos citados no início deste trabalho. Acredito que as preocupações expressas nas mensagens reflitam níveis de relações altamente complexas, não lineares e abstratas, operando em espaços de representação multidimensionais (como observado em redes conexionistas).

Coincidentemente, a partir desse ponto de desenvolvimento do grupo, há um aumento de "mensagens soltas" e uma diminuição drástica tanto no número de fios como no número de mensagens que compõem tais fios. E isso é altamente sintomático do nível de complexidade sistêmica atingido. As relações não mais se dão de maneira linear, em um ambiente bidimensional, mas multidimensional. As relações agora ocorrem, sobretudo, de forma indireta, não sendo mais captadas pelos fios. Isso também fica bastante evidente nas mensagens transcritas no início deste trabalho. Os exemplos dos fios no Quadro 1 acima parecem indicar, acima de tudo, processos de 
chunking, que são construções em um nível mais complexo de sistematização. Acredito que uma análise mais qualitativa do conteúdo das mensagens revele mais claramente esses novos graus de conectividade e interação, cujos indícios pudemos observar nos dados do grupo aqui analisados.

\section{Considerações finais}

Este trabalho buscou fazer uma comparação entre o desenvolvimento de um grupo de discussão assíncrono em CMC e uma rede neural (mais especificamente, um léxico mental) utilizando reflexões teóricas recentes acerca da cognição humana. Vimos que à medida que o grupo foi interagindo e se adaptando ao meio ao longo das semanas (um processo natural de desenvolvimento sistêmico), mais e mais conexões foram sendo feitas e regulações e restrições de toda ordem foram moldando o desenvolvimento da rede. Processos de regulação são o que mantêm uma rede dinâmica, e observamos fenômenos ao longo do desenvolvimento do grupo de discussão que poderiam ser considerados "erros" numa interlíngua. Por exemplo, em um nível mais formal, nossa produção textual foi sendo aos poucos calibrada em decorrência dos diferentes padrões observados, implicando constantes (re)adequações da terminologia e fraseologia utilizadas pelos membros do grupo. Também, em um nível mais pragmático, foi sendo adquirido um conhecimento de toda uma "cultura" própria acerca dos procedimentos adequados a serem observados pelos membros da "comunidade".

As recentes teorizações no campo da Lingüística Cognitiva, Psicologia Cognitiva e Ciências da Cognição em geral têm contribuído enormemente para a área de aquisição de segunda língua (SLA), possibilitando uma nova compreensão acerca da representação do conhecimento (não apenas lingüístico), dos processos de mapeamento entre forma e significado e dos próprios mecanismos subjacentes à aquisição de uma língua. Em especial, modelos conexionistas de representação, desenvolvimento e estruturação do conhecimento são uma alternativa bastante promissora para a compreensão dos processos de SLA (como sugere ELLIS, 2001, 2003). De uma forma metafórica, este trabalho buscou, acima de tudo, tornar tal paradigma um pouco mais 
palpável para aqueles que ainda não estão familiarizados com a filosofia conexionista no âmbito brasileiro dos estudos em SLA.

\section{Referências Bibliográficas}

ELLIS, N. C. Memory for language. In: ROBINSON, P. (Ed.). Cognition and Second Language Instruction. Cambridge: Cambridge University Press, 2001. p. 33-68.

ELLIS, N. C. Constructions, Chunking, and Connectionism: The Emergence of Second Language Structure. In: DOUGHTY, C.; LONG, M. (Eds.). The Handbook of Second Language Acquisition. Oxford, UK: Blackwell, 2003. p. 63-103.

ELMAN, J. L. An alternative view of the mental lexicon. Trends in Cognitive Science, v. 8, n.7, p. 301-306, 2004.

ELMAN, J. L. et al. Rethinking Innateness: a connectionist perspective on development. Cambridge, MA: Bradford/MIT Press, 1998. 447p.

MEARA, P. The dimensions of lexical competence. In: BROWN, G. et al. Performance \& Competence in Second Language Acquisition. Cambridge: Cambridge University Press, 1996. p. 35-53.

PINKER, S. The Language Instinct. London: Penguin Books, 1994. 494p. SINGLETON, D. Lexis and the lexicon: some general considerations. In: SINGLETON, D. Exploring the Second Language Mental Lexicon. Cambridge: Cambridge University Press, 1999. p. 8-38. 